\title{
TURKISH-SPEAKING CHILDREN'S COMPREHENSION OF ENGLISH RELATIVE CLAUSES: SUBJECT / OBJECT ASSYMETRY
}

\author{
Türkay Bulut
}

\begin{abstract}
Relative clauses in Turkish and in English differ syntactically. While in English, a head-initial language, the relative clause together with a relative pronoun modifies the immediately preceding noun phrase, in Turkish, a head-final language, there is no relative pronoun and the relative clauses precede the head noun. The findings obtained from the studies generally focusing on the acquisition of English relative clauses have shown that there is a hierarchy from most accessible for relativization to least accessible, which is named as the Noun Phrase Accessibility Hierarchy (NPAH) hypothesis. One of the purposes of this study is to investigate whether 910 year-old Turkish -speaking children learning English follow this hierarchy and find subject relative (SR) clauses easier to process than object relative (OR) clauses. The findings obtained from the picture-selection task have shown that the participants follow the hierarchy proposed by NPAH and that the learners process SR clauses easier than OR clauses. The reason of such outcome can be explained by the Structural Distance Hypothesis. Another purpose of this study is to find out whether the presentation type affects the comprehension of SR and OR clauses. For this purpose each item was presented with an imperative or a question. The analyses of the data have revealed that the presentation type may be a factor affecting the comprehension since the students have comprehended the clauses presented with an imperative better than those presented with a question. This may be due to the fact that the frequency of using imperative sentences may be higher than that of the questions in the classroom input. The other purpose of the study is to analyze whether the errors made by the learners are reversal errors or head errors. The students made more reversal errors and fewer head errors indicating that they significantly comprehended the head of the NP.
\end{abstract}

Key words: Subject relative clauses, object relative clauses, Noun Phrase Accessibility Hypothesis (NPAH), Linear Distance Hypothesis, Structural Distance Hypothesis. 


\title{
TÜRKÇE ANADÍL KONUŞURU ÇOCUKLARIN INGILIZCE ILGI TÜMCECIKLERINİ ANLAMASI: ÖZNE/NESNE BAKIŞIMSIZLIĞI
}

\begin{abstract}
Özet
Sözdizimsel olarak Türkçe ve İngilizce ilgi tümcecikleri farklllık gösterirler. Başönde bir dil olan Ingilizcede ilgi adll ile ilgi tümcecikleri baş adl takip ederken, baş-sonda bir dil olan Türkçede ilgi adll yoktur ve ilgi tümcecikleri baş adın önüne getirilir. İngilizce ilgi tümceciklerinin edinimi üzerine yoğunlaşan çalışmaların sonuçları Ad Öbekleri Erişim Siralaması (Noun Phrase Accessibility HierarchyNPAH) savında öne sürülen ilgilendirme sıralamasını desteklemektedir. Bu çalısmanın amacl, İngilizce öğrenen 9-10 yaş Türkçe anadil konuşuru çocukların, bu stralamayı takip ederek, özne ilgi (ÖI) tümceciklerini nesne ilgi (NI) tümceciklerinden daha iyi anlayıp anlamadıklarını incelemektir. Resim-seçme ölçeğinden elde edilen verilerin sayısal çözümlemeleri, katılımcıların anadillerinden sözdizimsel olarak farkl olan İngilizce öğrenirken, NPAH savinda öngörülen siralamaya uyduklarını ve özne ilgi tümceciklerini nesne ilgi tümceciklerinden daha iyi anladıklarını göstermektedir. Bunun nedeni alanyazında Yapısal Uzaklık Savı ile açıklanmaktadır. Ayrıca, sunum şeklinin öğrenicilerin anlamalarını etkileyen bir etmen olabileceği düşüncesiyle bu tümcecikler soru ve emir tümceleri içerisinde sunulmuştur. Bulgular, tümceciklerin sunum şekillerinin de ögrencilerin anlamaların etkileyen bir etmen olduğunu işaret etmektedir. Katılımcılar, emir tümceleri içerisinde sunulan ilgi tümceciklerini anlamada soru içerisinde sunulanları anlamadan daha başarılı oldular. Bu çalı̧̧mada incelenen son konu öğrenicilerin yaptıkları hataların tersine hatalar mı yoksa baş hataları mı olduğudur. Öğrenicilerin yaptıkları hatalartn incelenmesi sonucunda, onların tümcecikte bulunan ilk AÖ'yü kilıcı olarak yorumlamalarının neden olduğu baş hataların saylsinin tersine hataların sayısindan çok daha az olduğu bulunmuştur.
\end{abstract}

Anahtar kelimeler: Özne ilgi tümcecikleri, nesne ilgi tümcecikleri, Ad Öbekleri Erişim Stralaması Savı, Doğrusal Uzaklık Savı, Yapısal Uzaklık Savı. 


\section{Giriş}

Son yıllarda bir dil yapısını ayrıştırmanın, zihinsel bir işleme olduğu görüşünün yaygınlaşmasına bağlı olarak, zihinsel dilbilgisi ile dil işleme mekanizmaları arasındaki ilişkilere eğilen çalışmalara daha sık rastlanmaktadır. Bu çalışmalarda, ikinci veya yabancı dil (D2) öğrenicilerinin dil yapılarını anlayabilmeleri ve üretebilmeleri için, bu yapıları işlemelerinin, süreçlemelerinin gerekli olduğuna işaret edilmektedir (Clashen \& Felser, 2006; Rah \& Adone, 2010). Sözdizimsel açıdan diller arasında farklılık gösteren ilgi tümcecikleri, sıkça araştırılan dilbilgisel yapılar arasındadır. Örneğin, Türkçe ilgi tümcecikleri, İngilizce ilgi tümceciklerinden oldukça farklıdır. Baş-önde (head-initial) bir dil olan İngilizcede ilgi adıllarının bulunduğu ilgi tümcecikleri baş adı takip ederken, baş-sonda (headfinal) bir dil olan Türkçede ilgi adılı yoktur. Bunun yerine, boş bir ilgi adılı işleyicisi bulunmaktadır (Kornfilt, 2000). Boş işleyici ve gedik arasındaki sözdizimsel bağlantı eşdizinlemeyle gösterilmiştir:

(1)

Öİ : [ $\varnothing_{i}$ okul-a gid-en $]$ adam $_{i}$

NI: [adam-1n $\emptyset_{i}$ git-tiğ-i] okul

“-An ve -DIK sonekleri niteleyen tümceciğin en sağında bulunur. -An son eki ile 'hedeflenen ilgilendirme' niteleyen tümceciğin öznesidir. -DIK soneki ile 'hedeflenen ilgilendirme' ise yönelimli nesnedir” (Kornfilt, 1997, s. 58-59). Ayrıca ilgi tümceciğindeki eylem (git-), -An ve -DIK soneklerini alarak adlaşıp zamanı belirtmemektedir. İlgi tümceciğinin niteleme alanındaki boşluk, sözdizimsel hareketten doğan bağlı değişkendir. Taşınan öğe ya boş işleyicidir ya da ilgi tümceciğinin başıdır (Kornfilt, 1997). Taşımanın yanı sıra, özne ilgi tümceciklerindeki nesne belirtme durumu ile nesne ilgi tümceciklerindeki özne ise tamlayan durum ile belirtilmiştir.

Anadil ediniminde bu tümceciklerin işlenmesi belirgin bir sıralamaya göre olmaktadır (Slobin, 1982; Diessel ve Tomasello, 2005; Ekmekçi, 1990; Özcan, 1997; Çağrı, 2007; Özge, Marinis \& Zeyrek; 2010). Bu sıralama, alanyazınında Keenan ve Comrie (1977)'nin ileri sürdüğü Ad Öbekleri Erişim Sıralaması (Noun Phrase Accessibility Hierarchy-NPAH) savı ile açıklanmıştır. Bu sava göre, ilgilendirme sıralaması, ilgilendirmeye en çok erişilebilirden en az erişilebilene göre dizilmiştir:

$$
\begin{aligned}
& \text { Özne }>\text { dolaysız nesne }>\text { dolaylı nesne }>\text { ilgeç tümleci }>\text { iyelik } \\
& (>=\text { daha fazla erişilebilir })
\end{aligned}
$$


İlgi adılları sıralamada ilgi tümceciklerindeki konumlarına göre adlandırılmışlardır. $\mathrm{Bu}$, ayrıca en az belirtiliden en belirtiliye doğru yapılan bir sıralama olarak da gösterilmektedir (Yürekli, 2007). İngilizce özne ilgi (Öİ) tümcelerinde ad öbeğini (the girl) niteleyen ilgi tümceciğindeki (that kisses the boy) ilgi adıl1, tümceciğin özne konumundan çıkarılmıştır (Örnek 2a). Nesne ilgi (NI) tümceciklerinde ise aynı ilgi adılı dolaysız nesne konumundan çıkarılmıştır (Örnek 2b):

(2)

a. the girl [that - kisses the boy]

b. the girl [ that the boy kisses_- - ]

Çalışmamızın da odağı olan bu iki yapı üzerine yapılan çalışmalarda, anadillerini edinen çocukların Öİ tümceciklerini, Nİ tümceciklerinden daha önce edindikleri saptanmıştır (Slobin, 1982; Gibson, 1998; Diessel ve Tomasello, 2005; Adani, 2008). Türkçe ilgi tümceciklerinin edinimini üzerine yapılan çalışmalardan ilki Slobin (1982) tarafından yürütülmüştür. Çalışmasında Türkçeyi ve İngilizceyi anadil olarak edinen çocukların ilgi tümceciklerini nasıl edindiklerin inceleyen Slobin, Türkçe edinen çocukların, İngilizce edinen yaşıtlarından daha az sıklıkla ilgi tümceciklerini kullandıklarını saptamıştır. Slobin bunun nedenini bulmak için çocukların anne-babalarının ilgi tümceciklerini kullanım sıklığına baktığında ise Türkçe konuşan anne-babaların çocuklarına sağladığı dil girdisinde ilgi tümceciklerini daha az kullandıklarını ve en sık Öİ tümceciklerini kullanıldığını saptamıştır. Öte yandan Erguvanlı-Taylan ve Koç (1998), Türkçe anadil konuşmacılarının anlatılarında Nİ tümceciklerini daha fazla kullandıklarını bulmuşlardır.

Ekmekçi (1990), Türkçeyi anadili olarak edinen 3-6 yaş arası çocuklardan öykünme yöntemi ile topladığı verilere dayanarak, Öİ tümceciklerinin tekrarlanmasının Nİ tümceciklerine göre daha başarılı olduğunu bulmuştur. Araştırmacının üretme yöntemi ile topladığ verilerde ise çocuklar Nİ tümceciklerinde daha başarılı olmuşlardır. Bu konuda yapılan diğer çalışmaların sonuçları Ekmekçi'nin bulgusunu desteklememektedir (Çağrı, 2007). Özge, Marinis ve Zeyrek (2010), bu bulguların nedenini ölçekte kullanılan eylemlere bağlamışlardır. Öİ tümceciklerinde geçişsiz eylemlerin, Nİ tümceciklerinde ise geçişli eylemlerin kullanılması ilgi tümcecikleri arasındaki bakışımsızlığg etkileyen etmen olabileceğini ileri sürmüşlerdir. Özcan (1997) Türkçenin anadil ediniminde ilgi tümceciklerinin ana tümce içerisindeki yerinin etkisini sorgulayan ilk araştırmacıdır. Çalışmasında küçük çocukların (yaş ortalaması 3,5-5,5) ve büyük çocukların (yaş ortalaması $=7,6$ ) ilgi tümceciklerini anlamaların karşılaştırmış ve yaşla anlama arasında anlamlı bir bağ bulmuştur. Bu çalışmalardan elde edilen 
bulgulara göre, Türkçe edinen çocuklar Öİ tümceciklerini anlamakta Nİ tümceciklerinden daha başarılıdırlar.

Dilbilgisi yitimi (agrammatisim) olan Broca hastalarının ve anadil edinen çocukların dil işlemeleri arasında gözlemlenen benzerliğin D2 konuşurlarının aradillerinde de olabileceği varsayımıyla, bu hastaların dil işlemesi üzerine yapılan çalışmalar gittikçe önem kazanmaktadır (Aydın, 2007).

Yarbay-Duman, Aygen ve Bastiaanse (2008), anadili Türkçe olan yedi yetişkin Broca sözyitimi hastasında ilgi tümceciklerinin dilbilgisel aykırılığını (agrammatism) incelemek amaciyla bu hastalara resimler göstererek verilen tümceleri tamamlamalarını istemişlerdir (s.153):

(3)

Öİ tümceciği:

"Bu pijamayı diken adam ama bu ceketi ......."

Hastadan beklenen yanıt: diken kadın

Nİ tümceciği:

"Bu kadının diktiği pijama ama bu adamın......"

Hastadan beklenen yanıt: diktiği ceket

Hastaların her iki yapıyı da üretirken zorlandıklarını ve yapıların üretimleri arasında istatistiksel olarak anlamlı bir fark olmadığını bulmuşlardır. Öİ tümceciklerini doğru yanıtlama ortalamas $6,57(\% 32,8)$ iken Nİ tümceciklerini doğru tamamlama ortalaması 7 (\%35)'dir. Sonuç olarak araştırmacılar, baş adın işlevi ne olursa olsun bitimsiz tümcecik içeren tümceleri üretmenin Broca sözyitimi hastaları için genelde zor olduğunu bulmuşlardır. Bu tür hastaların ilgi tümceciklerini anlamaları üzerine ise Kükürt'ün (2004) bir çalışması bulunmaktadır. Kükürt, Broca sözyitimi hastalarında ve 41-52 aylık sağlıklı çocuklarda tümce-resim karşılaştırma ölçeği kullanarak ilgi tümceciklerini anlamalarını ölçmüştür. Öİ tümcecikleri anlama oranı çocuklarda \%88,2, Broca hastalarında ise $\% 90,9$ iken bu oranlar NI tümcecikleri için oldukça düşük bulunmuştur (çocuklarda \%47,1, Broca hastalarında \%27,3). Kükürt, bu hastaların Öİ tümceciklerindeki başarılarını öneylemcil konumunda bulunan ilk AÖ’ye kılıcı rolü vermelerine bağlamıştır.

Yabancı dil olarak Türkçe ilgi tümceciklerinin nasıl öğrenildiği üzerine alanyazında çok az çalışma bulunmaktadır. Bunlardan biri Aydın (2007) tarafından yürütülmüştür. $\mathrm{Bu}$ çalışmadan elde edilen bulgular, Türkçe Öİ tümceciklerini işlemenin Nİ tümceciklerini işlemeden daha kolay olduğu savını desteklemektedir. Ankara Üniversitesi'ne bağlı TÖMER'in Türkçe sınıflarına devam eden farklı 
Türkçe seviyelerine (başlangıç ve orta düzey) ve farklı anadillere (İngilizce, Japonca ve Korece) sahip 32 katılımcı ile 5 Broca sözyitimi hastasından resimseçme ölçeği kullanarak veri toplanan çalışmanın sonuçlarına göre, orta düzey katılımcılar Öİ tümceciklerini Nİ tümceciklerinden daha kolay anlamışlardır. Başlangıç düzeyindeki katılımcıların bu iki tümceciği anlamaları arasında ise anlamlı bir fark ortaya çıkmamıştır. Aydın'ın çalışmasından elde edilen başka bir önemli bulgu ise başlangıç seviyesindeki öğrencilerin yapmış oldukları hatalar ile Broca hastalarının yaptıkları hatalar arasında bir benzerlik olmasıdır. Aydın, katılımcıların Öİ tümceciklerini Nİ tümceciklerinden daha iyi anlamalarını Yapısal Uzaklık Savı (Structural Distance Hypothesis) ile açıklamıştır.

Türkçenin yabancı dil olarak öğrenilmesinde ilgi tümceciklerini işlemlemeyi araştıran bir başka çalışma da Özçelik (2006) tarafından yürütülmüştür. Amerika Birleşik Devletlerinde bulunan çeşitli üniversitelerde farklı alanlarda eğitim gören 27 öğrenciden (20 İngilizce, 7 Japonca, Moğolca ve Korece anadil konuşurları) resim-seçme ölçeği ile toplanan veriler, bu öğrencilerin Türkçe Öİ tümceciklerini daha zor işlemlediklerini göstermiştir. "D2 öğrenicileri, baş ile boşluk (gedik) arasındaki doğrusal uzaklığa duyarlılardır. Baş öğenin doğrusal olarak boşluğa daha yakın olduğu yapı onlar için daha kolaydır" (s. 4). Özçelik, bu zorluğun nedenini Doğrusal Uzaklık Savı (Linear Distance Hypothesis) ile açıklamıştır.

Bu sava göre, ilgi tümceciklerinin zorluğunu belirleyen etmen, Örnek 4' de de belirtildiği gibi, baş öğe (the lion) ve boşluk arasındaki sözcük sayısıdır. Yapısal Uzaklık Savına göre ise (Örnek 5), bu etmen baş (the man) ile boşluk ("e" olarak belirtilen) arasındaki öbek sınırlarının sayısıdır. Bu durumda hem Doğrusal Uzaklık Sav1 (iki öbek sınırı) hem Yapısal Uzaklık Sav1 (1 veya 0 sözcük), İngilizce Öİ tümceciklerini işlemenin daha kolay olduğunu ileri sürer.

(4)

a. ÖI tümcecikleri: the lion that [ _ carries the cow] 1 veya 0 sözcük

b. NI tümcecikleri: the lion that [the cow carries __ 4 veya 5 sözcük

(Özçelik, 2006, s. 6)

(5)

a. Öİ tümcecikleri: the man [CP who ${ }_{i}\left[\mathbf{I P} \mathrm{e}_{i}\right.$ loves the woman]] iki öbek sınırı

b. Nİ tümcecikleri: the man [CP who ${ }_{i}\left[\mathbf{I P}\right.$ the woman [VP loves $\left.\left.\left.\mathrm{e}_{i}\right]\right]\right]$ üç öbek sinırı

(Aydın, 2007, s. 297)

Ancak, Türkçe için durum farklıdır (Aydın, 2007, s. 297). Doğrusal Uzaklık Savına göre, Türkçe Nİ tümceciklerini anlamak Öİ tümceciklerini anlamaktan daha 
kolayken, Yapısal Uzaklık Savına göre Öİ tümceciklerini anlamak Nİ tümceciklerini anlamaktan daha kolaydır.

(6)

Doğrusal Uzaklık Savı

Öİ: [e $\mathrm{e}_{\mathrm{i}}$ kadın-1 sev-en] adam $_{\mathrm{i}}$ ("kadını" ve "seven”; iki sözcük)

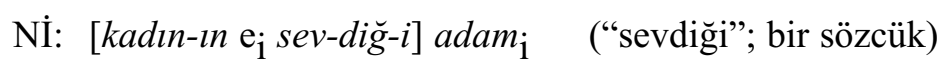

Yapısal Uzaklık Savı

ÖI: $\left[\mathrm{e}_{\mathrm{i}}\right.$ kadın-1 sev-en] adam $_{\mathrm{i}}$ (ZÖ, TÖ; 2 öbek sınırı)

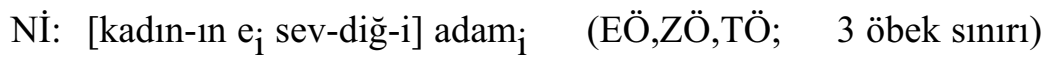

(Aydin, 2007, s. 300)

Özçelik'in (2006) çalışmasına katılanların Nİ tümceciklerini daha iyi anlaması, onun Doğrusal Uzaklık Savını desteklemesine yol açarken, Aydın'ın (2007) çalışmasına katılanların Öİ tümceciklerini daha kolay anlaması, onun Yapısal Uzaklık Savını desteklemesine neden olmuştur. Bu iki çlışmadan elde edilen verilerde gözlemlenen örtüşmemenin nedeni, Özçelik'in çalışmasına katılan öğrencilerin Türkçe dil girdisine erişimlerinin yeterli olmamasından, gerçekten orta düzey Türkçe seviyesinde olmamalarından kaynaklanmış olabilir. Zira katılımcılara verilen ve araştırmacı tarafından düzenlenen Türkçe dil seviye testi standart bir test olmayıp verilen yanıtların hangi ölçütlere göre dil düzeylerini belirlediği hakkında çalışmasında yeterli bir açıklama yapılmamıştır.

Farklı anadile sahip öğrenicilerin İngilizceyi öğrenmeleri üzerine yürütülen çalışmalardan elde edilen bulgular da Öİ tümceciklerinin öğrenilmesinin Nİ tümceciklerinin öğrenilmesinden daha kolay olduğu savını destekler yöndedir (Gass ve Selinker, 2001; Matsumoto, 2007; Yürekli, 2007; Aydın, 2007). Izumi (2003), dilbilgisel yargılama ve yorumlama ölçeklerini kullandığı çalışmasının sonunda, farklı anadilleri konuşan yetişkin katılımcıların İngilizce NI tümceciklerini anlamada ve kurmada Öİ tümceciklerinden daha fazla hata yaptıklarını bulmuştur. İngilizce öğrenen yetişkin Japonların ilgi tümceciklerini nasıl edindiğini sorgulayan Kadoi ( 2009), karşıtsal çözümleme yaklaşımı ile İngilizce ve Japonca arasındaki yapısal farklılıkları incelemiş ve Nİ tümceciklerinin anlaşılma zorluğunun nedenini Japoncada ilgi adıllarının bulunmamasına bağlamıştır. Ayrıca elde ettiği verilere Algılama Zorluğu Savı (Perceptual Difficulty Hypothesis-PDH) çerçevesinde baktığında ilgi tümceciklerinin ana tümce (matrix clause) içerisindeki yerlerinin de önemli olduğunu belirtmiştir (s. 20): 
- Ortaya yerleştirilmiş tümcecik: ana tümcenin öznesi-ilgi tümceciğinin öznesi (ÖÖ)

- The people who live in Philadelphia are busy.

- Ortaya yerleştirilmiş tümcecik: ana tümcenin öznesi-ilgi tümceciğinin nesnesi (ÖN)

- The people who we know live in Philadelphia.

- Sağa yerleştirilmiş tümcecik: Tümcenin nesnesi-ilgi tümceciğinin öznesi (NÖ)

- I know some people who live in Philadelphia.

- Sağa yerleştirilmiş tümcecik: Tümcenin nesnesi-ilgi tümceciğinin nesnesi (NN)

- I know the people who you know.

Bu sava göre, ortaya yerleştirilmiş İngilizce ilgi tümceciklerinin anlaşılması diğer yerleştirme yerlerine kıyasla daha zordur çünkü ana tümce işlemesi ile çakışır. Japoncada NÖ ve NN'nin, sola ve ortaya yerleştirilmiş biçimleri de doğrudur. Kadoi, İngilizce ilgi tümceciklerinin baş öğe olan ad ile ilişkisinin güçlü olduğunu ve ilgi tümceciklerinin sınıflandırılmasının bu güçlü ilişkiyi temel aldığını iddia etmiştir. Öte yandan Japonca ilgi tümceciklerinin baş ad ile böylesine güçlü bir ilişkisi olmadığından, Japonca anadil konuşucularının ilișkiye bağlamdan çıkarımla ulaştıklarını belirtmiştir. Kadoi çalışmasının sonunda, Japon yetişkinler için NÖ konumundaki İngilizce ilgi tümceciklerin en kolay, ÖN konumundakilerin ise en zor öğrenilen ilgi tümcecikleri olduğunu saptamıştır.

İngilizce öğrenen Japon yetişkinlerin ilgi tümceciklerini anlamalarını inceleyen bir başka çalışma ise (Hashimoto, 2007) işleme zorluğunun nedenlerini öğrenicilerin yeni bilgiyi işleyecek ve anlam, bağlam, yapı gibi dil özelliklerini anlamaya yetecek bilgilerinin olmamasına bağlamıştır. Araştırmacı bu çalışmada Nİ tümceciklerinin anlaşılmasının Öİ tümceciklerinin anlaşılmasından daha zor olma nedenini "anlamanın psikolojik kolaylığı" (s. 3) ve Ad Öbekleri Erişim Sıralaması (NPHA) sav1 ile ilişkilendirmiştir. Hashimoto, çalışmasına katılan 15 yetişkin Japon öğrencinin, Öİ ve Nİ tümceciklerini okuma sürelerini ölçmüștür. Elde ettiği verilere dayanarak, her iki yapı içinde ana eylemi okuma süresinin diğer sözcük türlerini okuma sürelerinden daha uzun olduğunu saptamıştır. Hashimoto buna neden olarak öğrencilerin ilgi tümceciğinin sonunda yer alan ana eyleme geldiklerinde, ana tümcenin özne konumundaki ad öbeğini hatırlamaya çalışmalarını göstermiştir. Ayrıca, öğrencilerin, Nİ tümceciklerini okumaları diğer bölümleri okumalarından daha uzun sürmüştür. Hashimoto bunun nedenini ise, Nİ tümceciklerinde bulunan eylem ile ana tümcenin eyleminin bitişik olmasına ve bu durumun öğrenicilerin hafızalarında karışıklık yaratmasına bağlamıştır. 
Baysal (2001) ve Yürekli (2007), Türk yetişkinlerin İngilizce ilgi tümceciklerini öğrenmesini NPHA savı çerçevesinde incelemişlerdir. Baysal (2001), orta düzey altı ve orta düzey üstü İngilizce dil seviyesine sahip 80 üniversite öğrenicisinden üç farklı veri toplama aracı (dilbilgisel doğruluk saptama, tümce bağlama ve çeviri) yardımıyla elde ettiği bulgulara dayanarak, iyelik ekinin NPHA sıralamasına uymadığını saptamıştır. Bu bulgular 1şığında iyelik eklerinin kendi içerisinde bir sıralama gösterip göstermediğini araştıran Yürekli (2007), farklı İngilizce seviyelerinde olan 80 üniversite öğrenicisine çeviri ve tümce birleştirme ölçekleri uygulamıştır. Elde ettiği verileri Jones'un (Yürekli, 2007, s. 109 içinde) önerdiği sıralama ile karşılaştırmış ve İngilizce öğrenen yetişkin Türk öğrencilerinin de bu sıralamaya uygun davrandığını bulmuştur. Katılımcılar, "the girl whose hat is extraordinary is from Hawaii" gibi ÖI +iyelik tümceciklerinde "the journalist whose interview I watched on TV died yesterday" gibi NI +iyelik tümcelerinden daha az hata yapmışlardır. Yürekli, çalışmasının sonunda, İngilizce belirtililik derecesinin ilgi tümceciğinin baş adının işlevi kadar +/- iyelik özelliğine de bağlı olduğu sonucuna varmıştır.

Alanyazında bulunan bu bulgular yetişkinlerin Türkçe-İngilizce aradillerinde ÖI tümceciklerini Nİ tümceciklerinden daha iyi anladıklarını göstermektedir. Bu çalışmanın amacı ise, 9-10 yaşlarındaki Türkçe anadil konuşurlarının Türkçeİngilizce aradillerinde, yetişkinlerin aradillerine benzer bir sıralama takip edip etmediklerini araştırmaktır. $\mathrm{Bu}$ amaçla, aşağıda verilen araştırma soruları oluşturulmuştur:

1) Bu çalışmaya katılan 9-10 yaşındaki çocuklar İngilizce Öİ tümceciklerini NI tümceciklerinden daha kolay mı anlayacaklar?

2) Katılımcılar tersine hataları $\mathrm{m} ı$ (reversal errors) yoksa baş hataları $\mathrm{m} ı$ (head errors) daha çok yapacaklar?

3) $\mathrm{Bu}$ tümceciklerin soru veya emir tümceleri ile sorgulanma yöntemi öğrencilerin anlamalarını etkileyecek mi?

\section{2. Çalışma}

\section{1 Örneklem}

Araştırmanın örneklemini 2011-2012 eğitim öğretim yılında, İstanbul ili Kadıköy ilçesinde iki farklı özel ilköğretim okuluna devam eden 9-10 yaşları $(\mathrm{x}=9,36)$ arasındaki 80 öğrenci oluşturmaktadır. Bunların tamamı şu anda devam ettikleri okullara okul öncesi eğitimle başlamışlardır. $O$ yaşlardan beri çoğunluğu anadili İngilizce olan öğretmenlerden sınıf ortamında haftada 11 saat İngilizce dersi almaktadırlar. Ayrıca bu okullarda çocuklara daha fazla İngilizce dil girdisi 
sağlamak amaciyla müzik ve resim dersleri de, anadili İngilizce olan öğretmenler tarafından verilmektedir. Öğretmenlerin sınıf içerisinde kullanmak üzere seçtikleri ders kitapları, alt-orta düzey (pre-intermediate) öğrenciler için hazırlanmış olduğundan bu çalışmada katılımcıların İngilizce dil düzeyi olarak bu düzey kabul edilmiştir. Yapılan görüşmelerde öğretmenler sınıf içerisinde ilgi tümceciklerini henüz açıkça öğretmediklerini ama öğrencilerin bu yapıları anlayıp üretebildiklerini belirtmişlerdir. Ayrıca anadili İngilizce olan 15 katılımcı da bu çalışmada kontrol grubu olarak alınmıştır. Bu katılımcıların yaş ortalaması 27, Türkiye'de bulunma sürelerinin ortalaması ise 14 aydır.

\subsection{Veri Toplama Aracı}

Çalışmanın amacı olan ilgi tümceciklerinin anlama işlemini araştırmak için kullanılan resim-seçme ölçeği Özçelik'in (2006) kullandığı ölçekten uyarlanmıştır. Resim-seçme ölçeği, 9-10 yaşlarında olan bu çocukların "zıtlıklara olan duyarlılıkları" (s.18) yoluyla onların bu yapıları anlamalarını ortaya çıkarmaya yardımcı olabilir. Ölçekte her bir sayfada birbirine benzer üç resim olmak üzere toplam 30 farklı resim bulunmaktadır. Çalışmanın amaçları arasında ilgi tümceciklerinin ana tümce (matrix clause) içerisindeki yerlerinin etkisini araştırmak olmadığından, tüm tümcelerde Öİ ve Nİ tümceciklerinin yerleri sabit tutulmuştur. Özge, Marinis \& Zeyrek'in (2010) çalışmaları takip edilerek, tümceciklerin sunum şekillerinin öğrencilerin anlamalarını etkileyen bir etmen olup olmadığını araştırmak için bazı resimler emir, bazıları ise soru yapıları kullanılarak sunulmuştur:
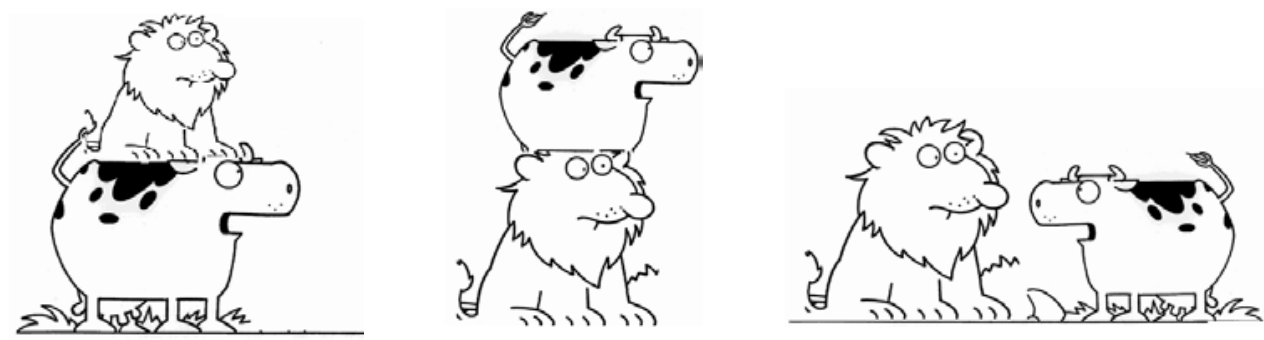

a) Öİ tümcecikleri içerenler (emir tümceleri:5; soru tümceleri:5; toplam:10) Mark the cow that carries the lion!

Öİ tümceciğini doğru olarak anlayan öğrencilerin birinci resmi seçmeleri beklenmektedir. İkinci resim yanlış, "carry" eyleminin olmadığ 1 son resim ise çeldirici olandır.

b) Nİ ilgi tümcecikleri içerenler (emir tümceleri:5; soru tümceleri:5; toplam:10)

Which one is the cow that the lion carries? 
Nİ ilgi tümceciğini doğru olarak anlayan katılımcıların yukarıda verilen üç resimden ikincisini seçmesi beklenmektedir. $\mathrm{Bu}$ sefer birinci resim yanlış olandır. Son resim yine çeldirici olarak ölçeğe eklenmiştir.

c) Kontrol tümceleri (emir tümceleri:5; soru tümceleri:5; toplam:10)

Mark the man in the car!

Özçelik (2006) öğrencilerin sadece ilgi tümcecikleri yapılarının ölçüldüğünü anlamamaları için ölçeğe çeldirici amaçlı kontrol tümceleri eklemiştir. Bu çalışmaya katılanlara ise henüz ilgi tümceciklerini dilbilgisi konusu olarak sınıf içerisinde çalışmadıkları için bu on kontrol tümcesi benzer yapıların sürekli kullanılmasının sıkılmaya ve dolayısıyla dikkat dağılmasına neden olacağ 1 düşüncesiyle eklenmiştir. Ayrıca, resimlerin ve sunum (emir veya soru) şekillerinin sıralaması da çeşitlendirilmiştir. Anlamsal olarak iki yönlülüğü (semantically reversible) sağlayabilmek için sadece insan veya hayvan resimleri kullanılmıştır. Cansız nesneler resimlerde kullanılmamıştır (Bkz. Ek 1).

\section{3 İşlem}

Öğrencilere resimlerin bulunduğu kitapçıklar dağıtıldıktan sonra şu açıklama yapılmıştır: "Bu kitapçığın her sayfasında üç ayrı resim göreceksiniz. Resimlerdeki kişi veya hayvanları betimleyen tümceleri öğretmeniniz sizlere sadece bir kez okuyacak. Tekrar etmeyecek. Bu tümcede betimlenen kişinin veya hayvanın üzerine çarpı işareti koyunuz. Sadece ve sadece ben 'Tamam' dedikten sonra diğer sayfayı çeviriniz. Aynı resimler kitapçık içerisinde tekrar kullanılmıştır. Lütfen bunun için hazırlıklı olun. Tümcelerde sizin bilmediğiniz bir kelime olmadığını öğretmeniniz onaylamıştır. Bu süre içerisinde lütfen sessiz olmaya çalışalım. Katılımınız için teşekkür ederiz."

Araştırmacının bu açıklamayı yüksek sesle iki kez okumasının ardından, öğrenicilerden gelen sorular yanıtlanmıştır. Sınıf testi almaya hazır olunca, anadili İngilizce olan sınıf öğretmeni, resimler için hazırlanan her tümceyi yüksek sesle sadece bir kez okumuştur. Öğrencilerin doğru resmi işaretlemeleri için beş saniye bekleyen araştırmacı yüksek sesle "Tamam" dedikten sonra öğrenciler sayfayı çevirip yeni resimleri görmüşlerdir. Okulların stajyer öğretmenleri de öğrencilerin aynı anda sayfaları çevirip çevirmediklerini denetlemek amacıyla sınıf içerisinde görev yapmışlardır.

Toplanan veriler nicel çözümleme yapabilmek amacıyla SPSS 11.5 paket programına yüklenirken, doğru işaretlemeler için 1 , hatalı olanlar için ise 0 kodu kullanılmıştır. Daha sonra seçimler arasında gözlemlenen farklılıkların istatistiksel 
olarak anlamlı olup olmadığını saptamak için t-test uygulanmıştır. Ayrıca, O'Grady, Lee, ve Choo (2003) ve Aydın (2007) takip edilerek hatalı yorumlar kendi içerisinde tersine çevirme (reversal) ile mi yoksa baş ile mi ilgili olduğu araştırılmıştır.

1

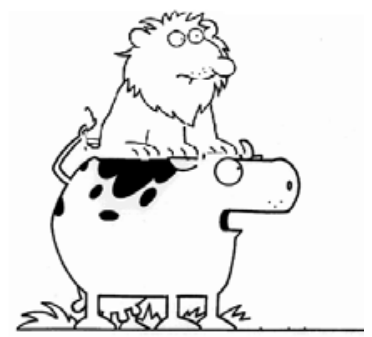

2

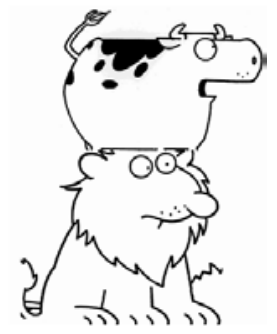

3

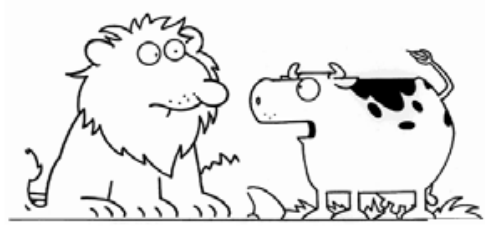

Öİ: "Mark the cow that carries the lion!"

NI: "Mark the cow that the lion carries!"

Öİ tümcecikleri için, katılımcıların hatalı yorumlayarak ikinci resimdeki ineği işaretlemeleri durumunda, bu işleme Öİ tümceciklerindeki "tersine hatalı yorumlama" (reversal errors) denmiştir. Bunun nedeni Öİ tümceciğinin Nİ tümceciği (the cow that the lion carries) gibi yorumlanmış olmasına karşın baş adın doğru tanımlanmış olmasıdır. Katılımcıların ikinci resimdeki aslanı işaretlemeleri durumunda da bu işlem Öİ tümceciklerinde "baş hata" (head error) (Aydın, 2007, s. 303) olarak adlandırılmıştır. Bunun nedeni de "the lion" ad öbeğinin tümcedeki ilgi tümceciğinin başı (The lion that carries the cow) gibi yorumlanmış olmasıdır. NI tümceciklerinde ise, katılımcılar birinci resimdeki ineği seçerlerse bu onların NI tümceciğini Öİ tümceciği gibi yorumladıklarını göstermektedir. Bu durum tersine hata yapmış olduklarının belirtisidir. Eğer birinci resimdeki aslanın üzerine çarpı işareti koyarak hatalı seçim yapmışlarsa, bu da onların baş hatası yaptıklarının göstergesidir.

\subsection{Bulgular ve Tartışma}

Araştırmanın kontrol öbeği olan İngilizce anadil konuşurları $(n=15)$ Öİ tümceciği içeren tümceleri \%98, Nİ tümceciği içeren tümceleri ise \%96 oranında doğru yapmışlardır. Elde edilen bu yüksek oranlar, çalışmanın veri toplama aracında kullanılan resimlerin ve tümcelerin doğru bir şekilde hazırlandığını göstermektedir. Resimlerin soru veya emir tümceleri kullanılarak sorgulanması arasında bir fark gözlemlenmemiştir.

Öğrencilerin sürekli ilgi tümcecikleri içeren tümceleri dinlemelerinin yorucu ve sıkıcı olabileceği düşüncesiyle ölçeğe eklenen kontrol amaçlı tümcelerden elde 
edilen verilere göre, katılımcıların \%95'i bu tümcelerle betimlenen resimlerdeki kişi veya hayvanları doğru işaretlemişlerdir. Kontrol tümcelerinin emir ("Mark the rabbit in the box!") veya soru yöntemi ("Which one is the rabbit in the box?") ile sunulmasının, anlamalarını anlamlı bir fark göstererek etkilemediği saptanmıştır.

Çizelge 1'de öğrencilerin Öİ ve Nİ tümceciklerini doğru ve yanlış anlama sıklık ve yüzdeleri sunulmuştur. Çalışmamızın birinci araştırma sorusu, Öİ tümceciklerinin Nİ tümceciklerini anlamaktan daha kolay olup olmadığıyla ilintiliydi. Resim-seçme ölçeğinden elde edilen bulgular, katılımcıların İngilizce Öİ tümceciklerini \%95 oranında doğru, $\% 5$ oranında yanlış anladıklarını göstermektedir. Nİ tümcecikleri için ise doğru işaretleme oran $\% 73$, yanlış işaretleme oranı ise $\% 27$ 'dir.

Çizelge 1: Öİ ve Nİ Tümceciklerinden elde edilen verilerin sıklık ve yüzde dağılımı

\begin{tabular}{|l|l|l|l|}
\hline & DOĞRU & YANLIŞ & $\begin{array}{l}\text { TOPLAM } \\
(10 \text { tümce X } 80 \text { öğrenci= 800) }\end{array}$ \\
\hline Öİ & $759(\% 95)$ & $41(\% 5)$ & $800(\% 100)$ \\
\hline Nİ & $587(\% 73)$ & $213(\% 27)$ & $800(\% 100)$ \\
\hline
\end{tabular}

Çizelge 1'de de görüldüğü gibi, 80 öğrenciden 10 adet Öİ tümceciği için elde edilen yanıt sayısı toplamda 800 'dür. Aynı şekilde Nİ tümcecikleri için de toplam 800 yanıt elde edilmiştir. Yanlış verilen yanıtların sayısı Nİ tümcecikleri için oldukça yüksektir. Öİ tümceciklerinin tamamını doğru bilen öğrenci sayısı 43'dür. Nİ tümcelerinin tamamını ise sadece 10 öğrenci doğru anlamıştır. Bu sayılar arasındaki farkların istatistiksel çözümlemeleri Çizelge 2'de sunulmuştur.

Çizelge 2: Öİ ve Nİ Tümceciklerinden elde edilen verilerin sayısal dağılımı

\begin{tabular}{|l|l|l|l|l|l|l|}
\hline & $\begin{array}{c}\text { Ortalama } \\
\mathrm{X} \square\end{array}$ & \multicolumn{1}{|c|}{$\begin{array}{c}\text { Standart } \\
\text { sapma }\end{array}$} & $\begin{array}{c}\text { Korelasyon } \\
(\mathrm{r})\end{array}$ & $\mathrm{p}$ & $\mathrm{t}$ & $\mathrm{p}$ \\
\hline Öİ tümcecikleri & 9,49 &, 729 &, 540 &, 000 & 9,552 &, 000 \\
Nİ tümcecikleri & 7,34 & 2,311 & & & \\
\hline
\end{tabular}

$\mathrm{N}=80$; serbestlik derecesi (df): 79 
Ortalamalar arasındaki farkın sayısal olarak anlamlı olup olmadığını anlamak için t-test uygulanmıştır. Çizelge 2 'de de sunulduğu üzere, Öİ tümcecikleri için elde edilen ortalama ( $\mathrm{x} \square=9,49)$ ile Nİ tümceciklerinden elde edilen ortalama ( $\mathrm{x} \square=7,34)$ arasındaki fark istatistiksel olarak anlamlıdır ( $(79)=9,552 ; \mathrm{p}<0.001) . \mathrm{Bu}$ bulgular, Türkçe anadil konuşurlarından (Özge, Marinis \& Zeyrek, 2010) ve Türkçe'yi yabancı dil olarak edinenlerden (Aydın, 2007) elde edilen bulgularla örtüşmektedir. Hem anadilde hem D2'de Öİ tümceciklerini işleme Nİ tümceciklerinden daha kolaydır. $\mathrm{Bu}$ da Öİ tümceciklerinin gelişiminin Nİ tümceciklerinin gelişiminden daha önce olduğu savını destekler yöndedir (Özge, Marinis \& Zeyrek, 2010).

Çalışmanın ikinci araştırma sorusu, yapılacak hataların daha çok tersine hatalar mı yoksa baş hataları $\mathrm{m} 1$ olacağı yönündeydi. Çizge 1'de, Öİ tümceciklerine verilen hatalı yanıtların sıklık dağılımları sunulmuştur. Çizge 1'de sunulduğu üzere, Öİ tümceciklerinde toplam 41 hatalı işaretlemenin 20'si (\%49) tersine hata, 9'u (\%21) baş hatası ve 12'si (\%30) diğer hatalardır. Örneğin, yukarıda verilen resimlerden "Mark the cow that carries the lion" tümcesi için tersine hata yapan öğrenciler birinci resimdeki ineğin yerine ikinci resimdeki ineği işaretlemişlerdir. Bu İÖ tümceciğini NI (the cow that the lion carries) tümceciği gibi algılamışlardır. Benzer şekilde, Çizge 2'de gösterildiği gibi, Nİ tümceciklerinde yapılan toplam 213 hatalı işaretlemenin 144'ü (\%68) tersine hata, 45'i (\%21) baş hatası ve 24'ü (\%11) diğer hatalardır. Ad öbeğinin baş adı doğru algılandığı için baş hatası (head error) oranı düşüktür. Çizgelerde de sunulduğu üzere katılımcılar baş hatalarını daha az yapmışlardır. Bu bulgular Aydın'ın (2007) çalışmasına katılan birinci öbeğin (orta düzey Türkçe dil seviyesinde olan katılımcıların) yaptığı hata oranlarıla örtüşmektedir.

Çizge 1: Öİ tümceciklerinde yapılan hataların sıklık dağılımları

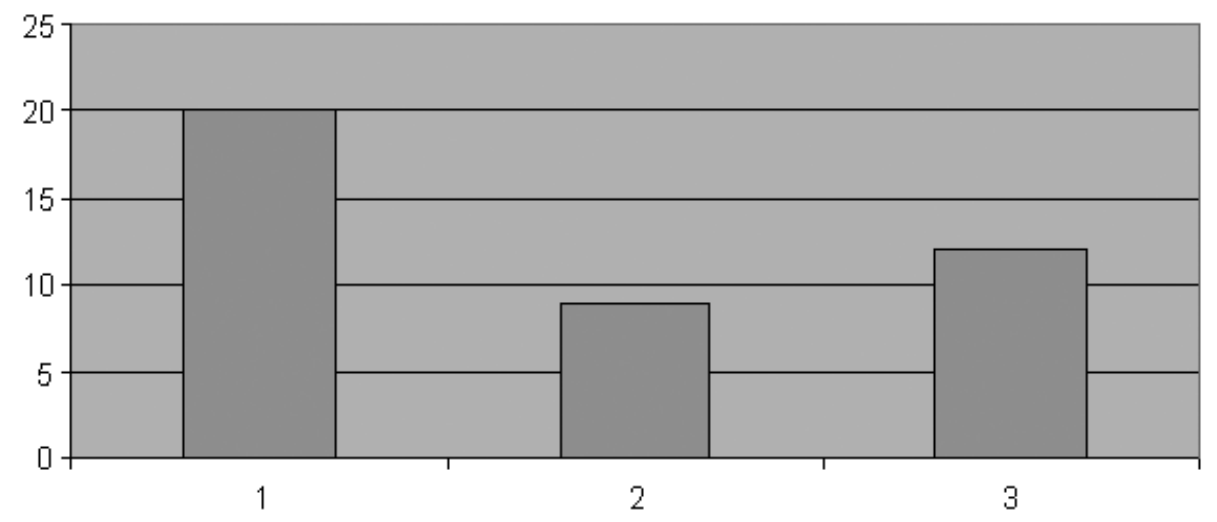


Çizge 2: Nİ tümceciklerinde yapılan hataların sıklık dağılımları

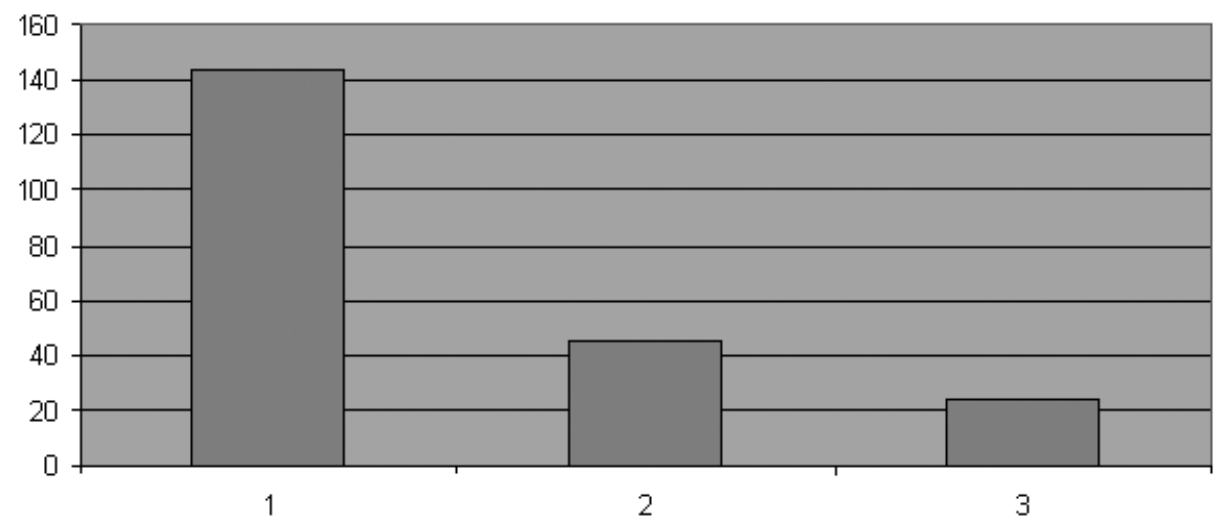

Çalışmanın araştırma sorularından sonuncusu Öİ ve Nİ tümceciklerinin emir veya soru tümceleri ile sunulmasının öğrencilerin ilgi tümceciklerini anlamalarını etkileyip etkilemediğiydi. Çizelge 3'de bu araştırma sorusuyla ile ilgili ölçekten elde edilen bulgular ve sayısal çözümlemeler sunulmuştur.

İlk olarak Öİ tümceciklerinden elde edilen bulgular incelendiğinde, bu tümceciklerin emir veya soru olarak sunulmasının sonucunda öğrencilerin elde ettiği ortalamalar (Öİ $\mathrm{x} \square=4,75 ; \mathrm{NI} \mathrm{x} \square: 4.74$ ) arasinda istatistiksel olarak anlamlı bir fark bulunmamıştır (t $(79)=0.191 ; p>0.05)$. Öİ tümceciklerinin emir veya soru tümceleri ile sorulması öğrencilerin bu tümceleri anlamalarını etkilememiş, her yöntemle bu tümcecikleri kolayca anlamışlardır.

Çizelge 3: Sunum yöntemleri ve ilgi tümceciklerini işlemleme arasındaki ilişki

\begin{tabular}{|c|c|c|c|c|c|c|c|c|}
\hline & Ortalama & $\mathrm{N}$ & \begin{tabular}{|l} 
Standart \\
Sapma
\end{tabular} & Korelasyon & $\mathrm{p}$ & $\mathrm{t}$ & \begin{tabular}{|l}
$\begin{array}{l}\text { Serbestlik } \\
\text { derecesi }\end{array}$ \\
\end{tabular} & $\mathrm{p}$ \\
\hline Öİ (emir) & 4,75 & 80 &, 436 & \multirow{2}{*}{,219 } & \multirow{2}{*}{,051 } & \multirow{2}{*}{, 191} & \multirow{2}{*}{79} & \multirow{2}{*}{, 849} \\
\hline Öİ (soru) & 4,74 & 80 & 497 & & & & & \\
\hline Nİ (emir) & 3,84 & 80 & 1,297 & \multirow{2}{*}{617} & \multirow{2}{*}{, 000} & \multirow{2}{*}{2,685} & \multirow{2}{*}{79} & \multirow{2}{*}{, 009} \\
\hline Nİ (soru) & 3,50 & 80 & 1,273 & & & & & \\
\hline Öİ (soru) & 4,74 & 80 & 497 & \multirow{2}{*}{, 410} & \multirow{2}{*}{, 000} & \multirow{2}{*}{9,534} & \multirow{2}{*}{79} & \multirow{2}{*}{, 000} \\
\hline Nİ (soru) & 3,50 & 80 & 1,273 & & & & & \\
\hline Öİ (emir) & 4,75 & 80 & ,436 & \multirow{2}{*}{,308 } & \multirow{2}{*}{,005 } & \multirow{2}{*}{6,612} & \multirow{2}{*}{79} & \multirow{2}{*}{, 000} \\
\hline Nİ (emir) & 3,84 & 80 & 1,297 & & & & & \\
\hline
\end{tabular}

Emir tümceleri kullanılarak sorgulanan Nİ tümcecikleri ise $(\mathrm{x} \square=3,84)$, soru tümceleri içerisine yerleştirilmiş Nİ tümceciklerinden $(\mathrm{x} \square=3.50)$ daha kolay 
anlaşılmıştır (t $(79)=2.685 ; \mathrm{p}<0.01)$. Emir tümceleri kendi içlerinde birbirleri ile karşılaştırıldığında ise Öİ emir tümcelerini anlamaları Nİ emir tümcelerini anlamalarından sayısal anlamlı bir farkla daha yüksek bulunmuştur $(\mathrm{t}(79)=6.612 ; \mathrm{p}$ $<0.001)$.

Benzer şekilde soru tümceleri ile sunulan ilgi tümceciklerinin anlaşılmasına baktığımızda Öİ içeren soru tümcelerini anlamaları Nİ içeren soru tümcelerini anlamalarından daha kolay olmuştur. Öİ cümlelerinde emir-soru tümcelerini anlamada aynı düzeyde başarı gözlenirken, Nİ cümlelerinde, emir tümcelerini anlama soru tümcelerini anlamadan daha başarılı şekilde gerçekleştirilmiştir. Özge, Marinis \& Zeyrek'in (2010) çalışmasına katılan Türkçe anadil konuşuru olan 5-8 yaşındaki çocuklar ise anlamsal olarak iki yönlü (semantically reversible) Öİ tümcecikleri soru ile sorgulandığında daha başarılı olmuşlardır. Bu durumda bu çalışmaya katılan öğrencilerin yaş olarak yakın olduğu yukarıda sözü edilen ve yaş olarak yakın oldukları çalışmaya katılan öğrencilerle(özellikle 8 yaş grubu "büyük çocuklarla") benzerlik göstermemesi, anadillerinden aktarım yapmadıkları ve aradillerinde farklı işlemleme içerisinde oldukları şeklinde de yorumlanabilir.

\section{Sonuç}

Bu çalışmanın amaçlarından biri 9-10 yaşlarında İngilizce öğrenen Türkçe anadil konuşurlarının aradillerinde, Öİ ilgi tümceciklerini Nİ tümceciklerinden daha iyi anlayıp anlamadıklarını araştırmaktır. Elde edilen bulgular, Kenan ve Comrie (1977) tarafindan öne sürülen Ad Öbekleri Erişim Siralaması (Noun Phrase Accessibility Hierarchy-NPAH) savının çocukların aradillerinde de geçerli olduğunu ve anlamsal olarak iki yönlü Öİ tümceciklerinin Nİ tümceciklerinden daha iyi anlaşıldığını göstermektedir. Bu da Yapısal Uzaklık Savını destekleyen bir bulgudur. Bu çalışmanın bir başka sorusu, öğrencilerin yapacakları hataların tersine hatalar $\mathrm{m} 1$ yoksa baş hataları $\mathrm{m} 1$ olacağ 1 ile ilgiliydi. Öğrencilerin hatalı işaretlemeleri bu açıdan incelendiğinde tersine hataların Nİ tümceciklerinde daha fazla yapıldığ 1 görülmüştür. Bu da Yapısal Uzaklık Savını destekleyen bir başka bulgu olarak kabul edilmiştir. Araştırmanın son sorusu tümceciklerin emir veya soru tümceleri ile sorulmasının öğrencilerin anlamalarını etkileyip etkilemediğiydi. Bulgular, öğrencilerin, emir tümceleriyle sorgulanmış Nİ tümceciklerini soru tümceleri ile sorulanlardan daha başarılı bir şekilde anladıklarını göstermiştir. Öİ tümceciklerinin ise emir veya soru tümceleri kullanılarak sorulması arasında sayısal olarak anlamlı bir fark bulunmamıştır. $\mathrm{Bu}$ da onların belirtisiz olan Öİ tümceciklerini daha belirtili olan Nİ tümceciklerinden önce öğrenmiş olduklarının göstergesi olabilir. 
Öİ ve Nİ tümceciklerini anlamada gözlemlenen bakışımsızlığın bu tümcecikleri üretmede de olup olmadığı araştırılması gereken bir konudur. Bunun için benzer yaşta ve benzer İngilizce düzeyine sahip öğrenicilerden öykünme yöntemi kullanılarak bu yapıların üretiminde de bakışımsızlık olup olmadığı araştırılabilir. İlgi tümceciklerinin ana tümce içerisinde farklı yerlerde kullanılmasının bu tümcecikleri üretmelerini etkileyip etkilemediği bir başka araştırılması gereken konu olabilir. Ayrıca, sınıf dil girdisinde kullanılan tümce türlerinin sıklığı ile öğrenicilerin emir tümceleri ile sorgulanan ilgi tümceciklerini soru tümceleriyle sorgulananlardan daha iyi anlamaları arasında bir bağlantı olup olmadığı da araştırılabilir.

\section{Kaynakça}

Adani, F. (2008). Re-thinking the acquisition of relatives: A new comprehension study with Italian children. Proceeding of the 27th West Coast, Conference in Formal Linguistics, University of California, Los Angeles, A.B.D.

Aydın, Ö. (2007). The comprehension of Turkish relative clauses in second language acquisition and agrammatisim. Applied Psycholinguistics, 28 (2), 295-315.

Baysal, A. (2001). The Noun Phrase Accessibility Hierarchy (NPAH) in the Acquisition of English Restrictive Relative Clauses by Turkish Adult Learners of English. Yayınlanmış doktora tezi, Anadolu Üniversitesi, Eskişehir.

Çağrı, I. (2007). Specificity and case interactions: A view from Turkish relatives. MIT Working Papers in Linguistics 54: WAFL II Proceedings. Cambridge, MA: MIT.

Clashen H. \& Fesler, C. (2006). Grammatical processing in language learning, Applied Psycholinguistics, 27, 3-42.

Diessel, H., \& Tomasello, M. (2005). A new look at the acquisition of relative clauses. Language, 81, 882-906.

Ekmekçi, Ö. (1990). Acquisition of relativization in Turkish. Fifth International Conference on Turkish Linguistics, SOAS, London University, England.

Erguvanli-Taylan, E. \& Aksu-Koç, A. (1998). Function of relative clauses in narrative discourse. L. Johanson (ed.) içinde, Proceedings of the Seventh International Conference on Turkish Linguistics (s. 271-285). Wiesbaden: Harrosowitz Verlag.

Gass, S. M. \& Selinker, L. (2001). Second Language Acquisition: An Introductory Course. Mahwah: NJ: Erlbaum.

Gibson, E. (1998). Linguistic complexity: Locality of syntactic dependencies. Cognition, 69, $1-76$.

Hashimoto, K. (2007). Subject/Object Asymmetry in the Comprehension of English Relative Clauses by Japanese Learners of English. University of Queensland Working Papers in Linguistics, Vol. 1, 22-34.

Izumi, S. (2003). Processing difficulty in comprehension and production of relative clauses 
by learners of English as a second language. Language Learning, 53(2), 285-323.

Kadoi, M. (2009). Acquisition English relative clauses by Japanese learners of English. TESOL Working Paper Series, 7 (1), 14-26.

Keenan, E. \& Comrie, B. (1977). Noun phrase accessibility and Universal Grammar. Linguistic Inquiry, 8, 63-100.

Kornfilt, J. (1997). Turkish. London: Routledge.

Kornfilt, J. (2000). Some syntactic and morphological properties of relative clauses in Turkish.

A. Alexiadou, P. Law, A. Meinenger, \& C. Wilder (Ed.) içinde, The Syntax of Relative Clauses (s.121-159). Amsterdam: John Benjamins Publishing Company.

Kükürt, D. (2004). Comprehension of Turkish relative clauses in Broca's aphasics and

children. Yayınlanmamış yüksek lisans tezi, Ortadoğu Teknik Üniversitesi, Ankara.

Matsumoto, Y. (2007). Interaction of multiple factors in relative clause construal and acquisition. Studies in Second Language Acquisition, 29, 367-374.

O'Grady, W., Lee, M., \& Choo, M. (2003). A subject-object asymmetry in the acquisition of relative clauses in Korean as a second language. Studies in Second Language Acquisition, 25, 433-448.

Özcan, F. H. (1997). Comprehension of relative clauses in the acquisition of Turkish. K.

İmer and E. Uzun (Ed.) içinde, Proceedings of the 8th international conference on Turkish linguistics, (s.149-155). Ankara.

Özge, D., Marinis, T. \& Zeyrek, D. (2010). Comprehension of subject and object relative clauses in monolingual Turkish children. S. Ay, Ö. Aydın, İ. Ergenç, S. Gökmen, S. İşsever \&

D. Peçenek (Ed.) içinde, Proceedings of the Fourteenth International Conference of Turkish Linguistics (ICTL), Wiesbaden: Harrasowitz Verlag.

Özçelik, Ö. (2006). Processing Relative Clauses in Turkish as a Second Language. Yayınlanmamış Yüksek Lisans Tezi, Pittsburgh Üniversitesi, PA, A.B.D.

Rah, A. \& Adone, D. (2010). Processing of the reduced relative clauses versus main verb ambiguity in L2 learners at different proficiency levels. Studies in Second Language Acquisition, 32, 79-109.

Slobin, D. I. (1982). Universal and particular in the acquisition of language. L. R. Gleitman \& E. Wanner (Ed.) içinde, Language Acquisition: State of the Art. Cambridge: CUP.

Yarbay-Duman, T., Aygen, G. \& Bastiaanse, R. (2008). The production of Turkish relative clauses in agrammatism: Verb inflection and costituent order. Brain and Language, $105,149-160$

Yürekli, A.(2007). The importance of genitive in assigning markedness degrees to English relative clauses. Dokuz Eylül Üniversitesi Buca Ĕgitim Fakültesi Dergisi, 21, 108114 . 
EK 1

RESIM SEÇME ÖLÇEĞİ

"Mark the woman that sees the man!"

"Mark the woman that the man sees!"

A
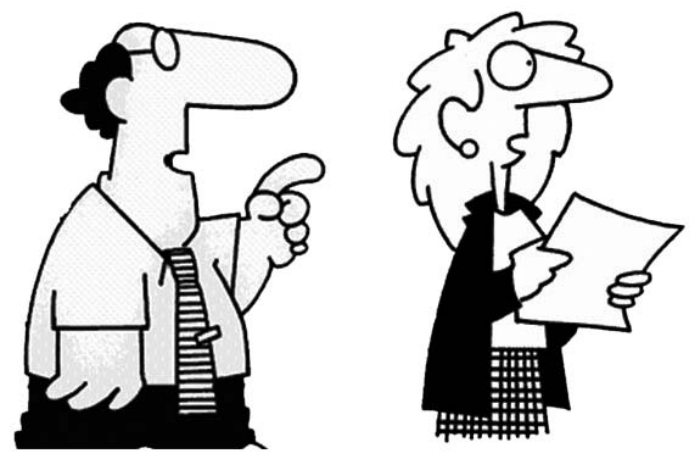

B

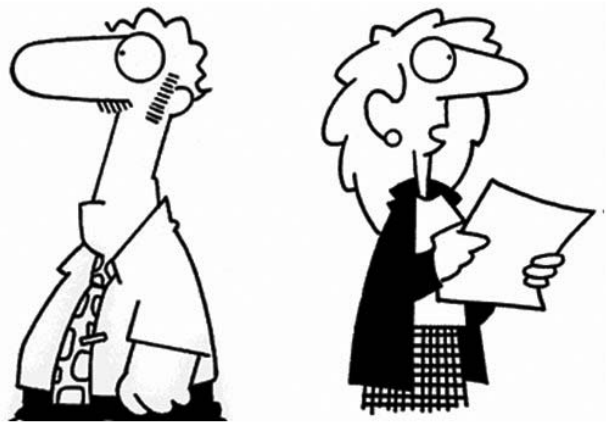

C

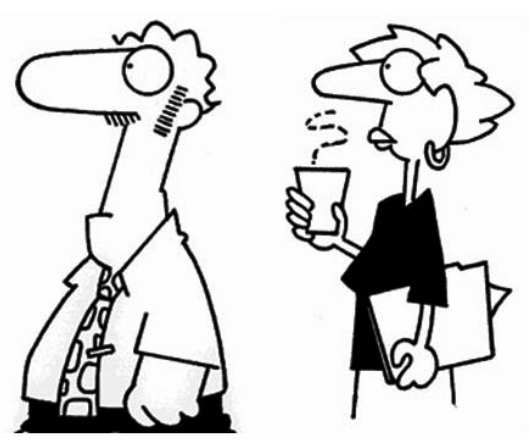

